\title{
Era Ekonomi Berkelanjutan: Studi literatur tentang Gerakan Bisnis Berkelanjutan
}

\author{
Aryati Dinta Kusumaningrum a,1,*, Dhian A. Safitra ${ }^{\text {b,2 }}$ \\ ${ }^{a}$ Kementerian Keuangan \\ b Politeknik Keuangan Negara \\ ${ }^{1}$ dintakusuma@gmail.com *; ${ }^{2}$ dhian.safitra@pknstan.go.id \\ * corresponding author
}

\section{ARTICLE INFO}

\section{Article history}

Received Desember 2019

Revised Januari 2020

Accepted Februari 2020

Keywords

Sustainable Economy

Environmental Economics

\section{ABSTRACT}

At present, awareness of the importance of maintaining environmental sustainability is increasingly widespread. The global community has also realized that this earth does not belong to this generation alone. In each period, various kinds of movements were introduced to encourage sustainable development. But what exactly is the difference between these proposed movements? This research with the literature review method will identify sustainable business movements from 1990 to the present. From the results of existing identification, this study will recommend which movements are realistic to implement in Indonesia, which has a unique character than other countries in the world.

JEL Code

Q56, Q58

\section{PENDAHULUAN}

Saat ini, upaya menyusun kebijakan pembangunan berkelanjutan diarahkan pada agenda Sustainable Development Goals (SDG's) yang dicanangkan oleh PBB (Smith et al., 2018). Berbagai konsep yang berbeda diperkenalkan dengan tujuan yang sama, pembangunan yang mempertimbangkan keberlanjutan lingkungan seperti green economy, blue economy, bioeconomy (D'amato, Droste, Winkler, \& Toppinen, 2019), circular economy (Sassanelli, Rosa, Rocca, \& Terzi, 2019) dan beberapa konsep lainnya. Tampaknya sama, namun pendekatan tiap konsep memiliki asumsi yang berbeda dan perbendaan strategi implementasi pada suatu negara yang memiliki perbedaan karakter geografis, tingkatan level pemerintah, pihak yang terlibat, atau perbedaan .pedoman pelaksanaan (D'amato et al., 2019).

Jika suatu negara memutuskan untuk mengimplementasikan salah satu konsep tersebut maka regulasi, penyediaan layanan publik, penggunaan pada instrumen ekonomi, dan penyediaan alat ukur perlu disesuaikan dengan asumsi yang ada pada konsep tersebut (D'amato et al., 2019). Apakah Indonesia merupakan salah satu negara yang peduli dengan ekonomi berkelanjutan? Peduli atau tidak, ini adalah suatu kebutuhan. Tercermin pada program kerja yang disusun pemerintah selama 2 kepemimpinan presiden terakhir. Pada era Presiden Susilo Bambang Yudhoyono, Indonesia mengumumkan pada konferensi PBB di Brazil (Rio+20) tahun 2012 bahwa kebijakan pembangunan di Indonesia mengadopsi konsep blue economy. Konsep yang digunakan untuk pengembangan industri perikanan di Indonesia dengan mempertimbangkan pembangunan dengan dampak lingkungan terkecil dengan menekan emisi karbon hingga tingkat nihil (Dinarto, 2017). Sebagai perwujudan komitmen atas pembangunan berkelanjutan yang ramah lingkungan, pada era Presiden Susilo Bambang Yudhoyono, terbit UndangUndang Nomor 3 Tahun 2014 tentang Perindustrian. Undang-Undang ini menyisipkan konsep industri hijau. Industri hijau sendiri didefinisikan sebagai industri yang memperhatikan efisiensi penggunaan sumber daya secara berkelanjutan dan memperhatikan kelestarian fungsi lingkungan. Pada kepemimpinan Presiden Joko Widodo juga, isu lingkungan menjadi pertimbangan pembangunan, ditandai pembangunan lingkungan menjadi salah satu dari 4 prioritas kerja Bappenas (Bappenas, 2017).

Namun konsep pembangunan berkelanjutan yang seperti apa yang dapat digunakan Indonesia? Mengingat banyak konsep-konsep yang diperkenalkan. Penelitian ini akan mengidentifikasi gerakangerakan bisnis berkelanjutan yang pernah dan masih populer dikampanyekan beserta perbandingan antar 
konsep. Dengan identifikasi ini, diharapkan penelitian ini dapat merekomendasikan satu konsep yang dapat diterapkan pada kebijakan pembangunan jangka panjang di Indonesia

\section{STUDI LITERATUR}

\section{Era sebelum 1980an}

\section{Recycling}

Sejarah konsep recycling hampir sama tuanya dengan isu terkait lingkungan. Namun, tidak ada dokumen secara pasti mendokumentasikan kapan konsep ini bermula (Cooper, 2010). Lienig and Bruemmer (2017) mendefinisikan recycling sebagai kegiatan mengubah material dari sampah menjadi material barang baru lainnya. Hal ini menjadi salah satu solusi konvensional atas keberadaan sampah yang biasanya hanya tertimbun pada lahan pembuangan akhir sampah. Recycling merupakan salah satu komponen dari gerakan yang dikenal pada era saat ini, "Reduce Reuse, dan Recycle".

Sumber tertulis yang dapat ditemukan mendokumentasikan bahwa, konsep recycling pertama kali dikenal di Jepang pada tahun 1031. Saat itu, kertas bekas sudah mulai diolah kembali untuk dijadikan kertas baru (Cleveland \& Morris, 2013). Tahun 1690 tercatat sebagai awal dari aktivitas recycling di koloni Amerika yang dikelola oleh William Rittenhouse yang memproduksi kertas dari kain dan kapas . Masih di Amerika, pada tahun 1896, kota sebesar New York telah memiliki sistem pengelolaan sampah yang memisahkan sampah sesuai jenisnya seperti barang yang masih bisa digunakan atau di daur ulang seperti kertas, besi, dan karet. 1904, Amerika telah memiliki tempat daur ulang aluminium skala besar di Chicago dan Cleveland (Cleveland \& Morris, 2013).

Konsep recycling yang berkembang pertama kali di Jepang dan hingga kini masih sering kita dengar merupakan salah satu konsep atau upaya mengampanyekan kebiasaan untuk menekan jumlah sampah yang diproduksi. Gerakan ini lebih dikenal dengan 3R (reuse, reduce, recycling) ini menggerakkan masyarakat untuk mengurangi jumlah sampah yang ditimbun di tempat pembuangan akhir (Tam \& Tam, 2006). Fokus dari konsep ini adalah sampah padat yang dihasilkan dari aktivitas manusia. Sejak pertama kali dicetuskan, konsep recycling terus berkembang, dan mengelompokkan tingkatan pengelolaan sampah, sebagaimana tergambar pada gambar 1 .

Gerakan recycling pada akhir tahun 1960 dan awal tahun 1970 di Amerika Serikat lebih dominan didorong oleh kelompok masyarakat dan lembaga non profit. Namun kelompok masyarakat lebih cenderung ke arah kampanye tanpa dibekali kemampuan membangun infrastruktur daur ulang, sehingga tidak efektif. Akhirnya pada akhir 1970, kampanye terkait daur ulang meredup. Mayoritas sampah padat ditimbun di tempat pembuangan akhir (Lounsbury, 1997). Tanpa peran serta pemerintah, infrastruktur pengolahan sampah menjadi barang publik yang tidak bisa atau tidak populer disediakan oleh swasta.

Walaupun kampanye dan pergerakan lingkungan hidup makin bervariasi, recylcing merupakan gerakan dan konsep yang pertama kali ada, dan masih cukup populer di mesin pencarian internet (Tóth, 2019). Permasalahan yang dihadapi atas kampanye gerakan recycling ini adalah strategi pemasaran. Shrum, Lowrey, and McCarty (1994) mengidentifikasi, agar konsep ini dapat berkelanjutan, [1] perlu menanamkan kesadaran akan pentingnya menekan jumlah sampah yang diproduksi, [2] perlu memberikan insentif agar konsep ini menarik, [3] publikasi, dan [4] keberlanjutan program. 


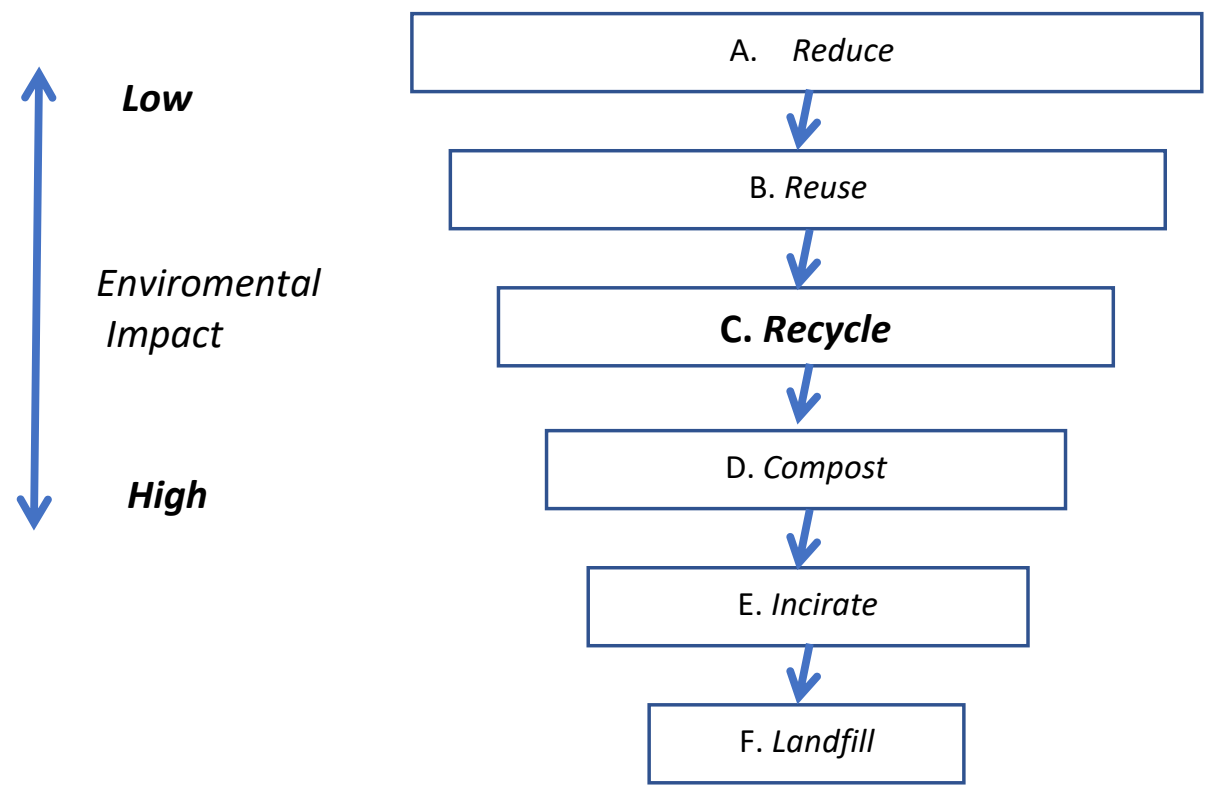

Gambar 1: Hirarki Pengelolaan Sampah

Sumber: (Tam \& Tam, 2006)

\section{Waste Minimization (1874)}

Waste Minimization meupakan pendekatan sistematis produksi untuk mengurangi limbah, dan jika memungkinkan, mencegah menghasilkan produk sampingan yang tidak diinginkan atau bahan limbah lainnya seperti emisi gas buang (Tóth, 2019). Ojovan, Lee, and Kalmykov (2019) mendefinisikan Waste Minimization sebagai proses atau aktivitas mengurangi jumlah bahan yang menghasilkan limbah hingga tingkat serendah mungkin atau dapat dicapai secara wajar. Konsep ini merupakan bagian dari hierarki pengelolaan sampah yang tertuang pada gambar 1 pada bagian reduce. Tujuan dari konsep waste minimization adalah menekan jumlah produksi sampah yang berbahaya untuk menghemat energi yang dipakai dengan membangun fasilitas pendukung pengolahan limbah. Pada akhirnya memiliki tujuan yang sama dengan konsep recycle karena mendorong bahan outpu produksi untuk digunakan kembali atas bahan baku yang masih bisa digunakan (reuse) dan diolah untuk menjadi bahan baku baru untuk produksi hal yang lain (recycle) (Rosenfeld \& Feng, 2011).

Konsep ini telah diperkenalkan pada tahun 1874 (Taylor, 1874) namun populer dan masif menjadi gerakan lingkungan pada era tahun 1990an. Lembaga-lembaga yang mengampanyekan saat itu adalah PBB, US EPA (United States Enviromental Protection Agency). Pada tahun 1984, konsep ini disepakati menjadi kebijakan nasional Amerika Serikat dalam bentuk amandemen Resource Conservation and Recovery Act (RCRA) (Hunter \& Benforado, 1987). Di Inggris Raya, pada tahun 1995 mengampanyekan kepada industri bahwa terdapat insentif dari penerapan waste minimization pada biaya produksi mereka. Untuk menyukseskan kampanye tersebut, pemerintah menginisiasi terbentuknya waste minimization clubs yang beranggotakan semua sektor produksi yang ada pada saat itu. Kampanye yang dilakukan Inggris Raya juga merujuk pada hirarki pengelolaan sampah dengan urutan waste minimization/reduce, reuse, recovery, dan disposal (Phillips, Pratt, \& Pike, 2001).

\section{Era Tahun 1980}

\section{Green Economy (1989)}

Terminologi green economy pertama kali digunakan dalam sebuah laporan bertajuk Blueprint for a Green Economy pada tahun 1989 yang dipersiapkan oleh ekonom yang peduli terhadap lingkungan untuk pemerintahan Inggris Raya (Barbier, 2010). Terminologi ini populer saat terjadinya krisis 2008 saat UNEP menginisiasi inisiatif yang dikenal dengan Green Economy Initiative untuk mendorong praktisi dan akademisi mendorong para politisi untuk mendukung investasi yang bergerak di sektor "hijau" serta mendorong industri konvensional yang menggunakan material serta menghasilkan polusi untuk lebih ramah lingkungan (Kasztelan, 2017). Tahun 2011, UNEP pun menyusun definisi dari green economy sebagai sistem ekonomi yang menghasilkan peningkatan kesejahteraan manusia yang berkeadilan sosial sekaligus secara signifikan mengurangi risiko lingkungan dan kelangkaan ekologis. Konsep ini 
mendorong industri untuk melakukan produksi rendah karbon, hemat sumber daya, dan inklusi sosial (Cameron \& Stuart, 2012).

Terdapat beberapa literatur terkait definisi green economy, pertama seperti yang di perkenalkan UNEP dimana green economy merupakan sistem kegiatan ekonomi yang berkesinambungan dari proses produksi, distribusi, dan konsumsi barang dan jasa yang menghasilkan peningkatan kesejahteraan manusia jangka panjang yang tidak menyisakan risiko buruk terhadap generasi mendatang terhadap masalah lingkungan dan kelangkaan ekologis (Cameron \& Stuart, 2012). Kedua, green economy didefinisikan sebagai sistem ekonomi yang tangguh memberikan peningkatan kualitas hidup, dengan memperhatikan batas ekologis planet (Green Economy Coalition, 2010). Ketiga, terdapat literatur juga yang mendefinisikan green economy sebagai perekonomian di mana pertumbuhan ekonomi dan kelestarian lingkungan berkolaborasi dengan cara saling menguatkan sambil mendukung pembangunan sosial. Bisnis dan industri merupakan stakeholde penting dalam memberikan produk, proses, teknologi, layanan, dan solusi yang layak secara ekonomi. (ICC, 2012). Selain itu, green economy juga didefinisikan sebagai perekonomian di mana pertumbuhan kesejahteraan rakyat dan peningkatan lapangan kerja tersedia namun negara memastikan pengurangan emisi dan pencemaran lingkungan yang merangsang menggunakan energi dan sumber daya secara efektif yang dapat mencegah segala kerusakan terhadap keanekaragaman hayati dan ekosistem (Diyar, Akparova, Toktabayev, \& Tyutunnikova, 2014)

\section{Era Tahun setelah 1990}

\section{Blue Economy (2010)}

Konsep blue economy diinisiasi oleh UN University pada tahun 1994. Saat itu, rektor UN Uneversity bekerja sama dengan pemerintah Jepang mengundang ekonom asal Belgia, Gunter Pauli, untuk mengembangkan konsep sistem ekonomi baru yang tidak menghasilkan limbah dan emisi, menciptakan lapangan pekerjaan, berkontribusi kepada social capital, dan tidak memerlukan biaya yang tinggi. Konsep ini dirancang untuk berdampingan dengan protokol Kyoto (Huxley, 2015). Huxley (2015) mendokumentasikan bahwa pada tahun 2004, konsep blue economy mulai memperlihatkan kemajuan. 340 inovasi telah teridentifikasi dan diserahkan ke sebuah tim yang berisi para praktisi dan akademisi. Inovasi ini dikerucutkan menjadi 100 inovasi terunggul, sayangnya proyek ini tertunda saat krisis finansial tahun 2008 menerpa dunia dan menyebabkan 50 juta orang di negara berkembang kehilangan pekerjaanya.

100 inovasi yang terpilih merupakan inovasi inspiratif yang mencerminkan kemampuan ekosistem usaha untuk selalu berevolusi dengan tingkat efisiensi yang lebih tinggi dengan sumber daya yang tersedia. 100 inovasi ini dibukukan dalam laporan Club of Rome dengan judul "Blue Economy” (Huxley, 2015). Inovasi-inovasi ini merujuk pada definisi blue economy yang diterjemahkan sebagai cara berproduksi yang berfokus pada alam dan mendorong perusahaan atau pengusaha untuk meniru alam dalam proses penciptaan produk (Pauli, 2010). Visi dari blue economy adalah [1] mengubah sampah menjadi nutrisi (dengan melakukan inovasi berbasis riset apakah kita dapat menciptakan industri tanpa limba), [2] cara berpikir baru tentang ekonomi dan manajemen (pasar ada karena ada kebutuhan yang harus dipenuhi), dan [3] the bio mimicry of system, di mana alam tidak memiliki konsep limbah (Bargh, 2014; Pauli, 2010).

Dalam prosesnya Pauli melakukan proyek sampingan dengan nama ZERI (Zero Emissions Research and Initiatives) di Swiss yang memiliki tujuan utama sebagai pionir mengimplementasikan inisiatif yang telah disusun dan membuktikan bahwa produk yang dihasilkan pada inisiatif ${ }^{1}$ tersebut layak secara ilmiah dapat diproduksi dan secara ekonomi layak dikonsumsi (Huxley, 2015). Aktivitas yang dilakukan Pauili ini bertujuan untuk "menginspirasi" industri untuk mengubah kerangka ekonomi untuk menggunakan apa yang dapat diolah dari muka bumi secara berkelanjutan dengan sebuah filosofi. Filosofi tersebut diadopsi dari konsep ekosistem di mana ekosistem merupakan desain yang luar biasa di mana semua materi dan energi yang ada pada ekosistem akan mengalir dari satu spesies ke spesies yang lain. Filosofi ini secara sederhana dapat dibahasakan bahwa limbah suatu spesies merupakan sumber energi dari spesies yang lain deengan bantuan prinsip fisika dan kimia (Bargh, 2014; Pauli, 2010)

\footnotetext{
${ }^{1}$ Salah satu inisiatif yang banyak menjadi rujukan adalah penggunaan limbah kopi untuk menumbuhkan jamur yang dipasarkan dan substratnya digunakan untuk pakan ternak yang kaya akan asam amino yang pada akhirnya menghasilkan zat yang ideal baki bakteri untuk mengekstraksi lebih banyak kotoran hewan (Pauli, 2010)
}

Aryati Dinta Kusumaningrum, et.al (Era Ekonomi Berkelanjutan: Studi literatur ...) 
Pauli (2010) mengkritik konsep gerakan lingkungan yang sudah ada karena hanya berfokus pada upaya mengurangi penggunaan sumber daya tidak terbarukan seperti bagaimana mengubah jagung menjadi biofuel atau bioplastic dan pada akhirnya tidak memberikan solusi yang holistik terhadap limbah yang terlanjur diproduksi sebuah industri, konsep ini lebih dikenal dengan nama green economy. Menurut Pauli (2010) dan Bullard and Müller (2012) konsep green economy perlu dikembangkan dan dikombinasikan dengan konsep atau ide laing agar dapat bertahan menghadapi triple crisis $^{2}$.

Dalam literatur lain, blue economy diterjemahkan dengan konsep ekonomi berkelanjutan dalam konteks kelautan. Everest-Phillips (2014) menerjemahkan blue economy sebagai ekonomi berbasis kelautan dengan pembangunan yang mengarah pada peningkatan kesejahteraan manusia dan keadilan sosial dengan mengurangi risiko lingkungan dan kelangkaan ekologis. Definisi ini secara konsep merupakan konsep green economy dalam konteks kelautan. Karena kesaamaan konsep, maka pada penelitian ini, definisi blue economy merujuk dengan konsep yang dipopulerkan oleh Pauli (2010).

\section{Circular Economy}

Konsep Circular Economy sedang populer beberapa tahun terakhir (Tóth, 2019), namun konsep ini dapat ditelusuri ada pada penelitian (Boulding, 1966), Pearce, Markandya, and Barbier (1989) dan Jackson (1993). Seiring waktu, konsep dan definisi circular economy berkembang sesuai sudut pandang peneliti. Kirchherr, Reike, and Hekkert (2017) merangkum 114 definisi circular economy menjadi sistem ekonomi yang menggantikan konsep "end-of-life" dengan mengurangi (reduce), menggunakan kembali (reuse), mendaur ulang (recycle), dan memperbaiki (recover) bahan atau peralatan pada proses produksi dan konsumsi. Siklus ini berlaku untuk skala ekonomi mikro (rumah tangga dan perusahaan) serta tingkat makro (tingkat wilayah kota, negara, dan wilayah sekitarnya) dengan tujuan pembangunan berkelanjutan sehingga secara bersamaan menciptakan kualitas lingkungan yang baik, kesejahteraan ekonomi, serta keadilan sosial yang mempertimbangkan kepentingan generasi sekarang dan masa depan. Konsep ini dapat tercipta dengan konsep bisnis yang baru dan konsumen yang bertanggungjawab.

Saat ini, konsep ini dipromosikan oleh Uni Eropa, beberapa pemerintahan, dan lembaga non pemerintahan di seluruh dunia. Konsep ini dinilai memiliki potensi untuk diterapkan secara meluas, karena dapat menarik berbagai macam bisnis dalam satu lingkaran bisnis yang berkesinambungan. Sumber daya yang terbatas akan dikelola secara berkelanjutan di mana di setiap rantai produksi menghasilkan nilai tambah atas sumber daya atau bahan baku yang sebenarnya sama (Korhonen, Honkasalo, \& Seppälä, 2018).

\section{METODE}

Kata kunci terkait konsep-konsep pembangunan berkelanjutan dan gerakan-gerakan bisnis berkelanjutan sangat mudah ditemukan di internet. Sehingga untuk mengidentifikasikan dan membandingkan konsep-konsep tersebut, memerlukan metode yang tepat, agar sumber yang digunakan dapat dipertanggungjawabkan. Memperhatikan aspek tersebut, penelitian ini menggunakan pendekatan studi pustaka sistematik (systematic literature review) yang dikembangkan Fink (2019). Fink (2019) mendefinisikan studi pustaka sistematik sebagai penelitian studi pustaka untuk mendefinisikan secara sistematik, eksplisit, dan komprehensif suatu topik permasalahan untuk mengidentifikasi kesenjangan penelitian dan menggambarkan penelitian yang telah dilaksanakan di masa lalu baik dari subjek dan objek penelitian, metode penelitian, dan hasil penelitian. Dengan metode ini, peneliti akan dapat menginventaris penelitian-penelitian yang dapat dilakukan di masa yang akan datang atau kemungkinan topik-topik penelitian yang tidak dipublikasikan (Fink, 2019).

Kata kunci yang digunakan untuk mencari sumber-sumber pustaka antara lain sustainability movement, sustainability development serta istilah-istilah yang mewakili konsep-konsep pembangunan berkelanjutan seperti recycling, waste, zero emmision, green economy, blue economy, circular economy, dan konsep-konspe lainnya. Kata kunci digunakan pada mesin pencarian google schoolar untuk meningkatkan peluang perolehan sumber tertulis berbasis tulisan ilmiah. Pencarian melalui mesin pencarian google tetap dilakukan untuk meningkatkan variasi informasi dari situs-situs sumber yang dapat dipercaya seperti situs pemerintahan atau lembaga-lembaga yang bergerak dibidang lingkungan.

\footnotetext{
2 Triple Crisis merujuk pada [1] krisis finansial, [2] perubahan iklim, dan [3] malnutrisi dan kelaparan (Addison, Arndt, \&
} Tarp, 2011)

Aryati Dinta Kusumaningrum, et.al (Era Ekonomi Berkelanjutan: Studi literatur ...) 
Penelitian ini hanya sebatas menginventaris topik-topik dan kata kunci yang berhubungan dengan konsep pembangunan berkelanjutan hingga tahap membandingkan definisi, konsep, dan implementasi. Penelitian selanjutnya dapat dikembangkan hingga pencarian kesenjangan penelitian terkait subjek dan objek penelitian, metode penelitian, dan hasil penelitian. Hal ini sejalan dengan tujuan penelitian ini untuk mengidentifikasi konsep-konsep pembangunan berkelanjutan dan merekomendasikan satu konsep yang dapat diterapkan di Indonesia.

\section{PEMBAHASAN}

Setelah dilakukan studi pustaka, maka disusunlah pemetaan teori, konsep dan pendekatan dari gerakan-gerakan dan konsep pembangunan berkelanjutan tersebut. Secara umum ternyata, recycle merupakan bagian dari hampir semua konsep yang ada. Untuk mengklarifikasi hubungan konsep tersebut, maka dapat dilihat hubungannya pada kerangka kerja yang ada pada gambar 2.

Pada awalnya, konsep-konsep yang diperkenalkan berbasis ekonomi lingkungan menitikberatkan pada pendekatan hierarki sampah, atau hanya berfokus pada bagaimana mengelola output dari suatu produksi (recycle dan Waste Minimization). Namun di era tahun 1980an, paradigmanya bergeser ke ekonomi ekologikal, atau pendekatan industri. Era ini telah mempertimbangkan bagaimana input suatu produksi tidak menghasilkan banyak output yang tidak berguna atau disposal output. Konsep hierarki sampah menjadi bagian dari konsep ini.

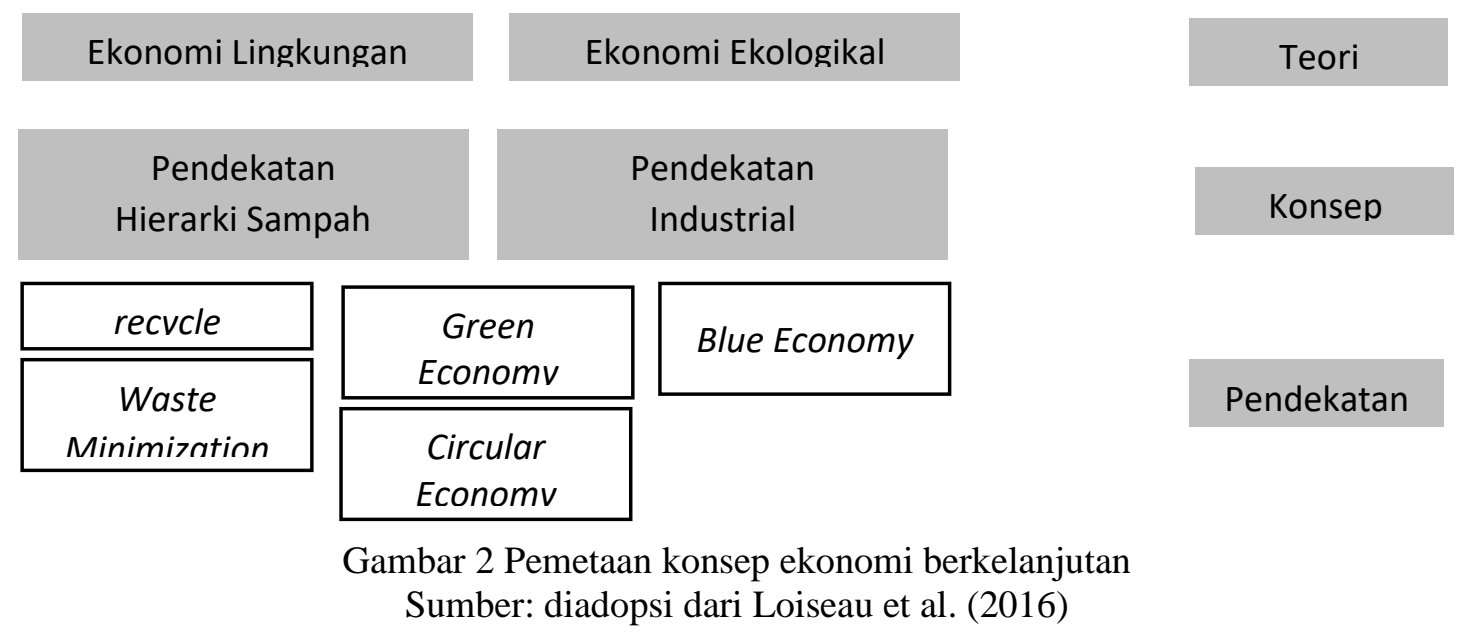

Pada akhirnya, beberapa konsep menjadi lebih holistik karena melihat perekonomian dari dua sisi, yaitu produsen dan konsumen seperti green economy dan circular economy. Ke dua konsep tersebut tetap mempertimbangkan disposal output dengan tetap memasukkan hirarki sampah pada definisinya. Artinya, tetap ada peluang bagian dari produksi atau konsumsi dilepas ke udara atau sampah pembuangan akhir, walaupun dalam jumlah yang tidak banyak.

Konsep blue economy yang populer sebagai pembaruan dari konsep green economy ternyata menawarkan sedikit konsep yang berbeda. Bahwa siklus produksi seharusnya mengadopsi konsep alam bekerja. Walaupun sepertinya sudut pandang yang digunakan lebih menitikberatkan dari sisi produksi, namun konsep ini memberikan perubahan yang cukup radikal, dimana suatu industri harus memikirkan seluruh output produksinya adalah input dari industri lainnya. Persis cara kerja alam, di mana tidak ada sampah, karena output dari suait organisme adalah sumber energi dan nutrisi dari organisme lainnya.

Dari perbedaan konsep tersebut, dapat disusun sebuah klasifikasi konsep, sebagai alat untuk menempatkan dan menentukan, kebijakan mana yang ideal diterapkan di Indonesia. Klasifikasi konsep tersebut dapat dilihat pada gambar 3. 


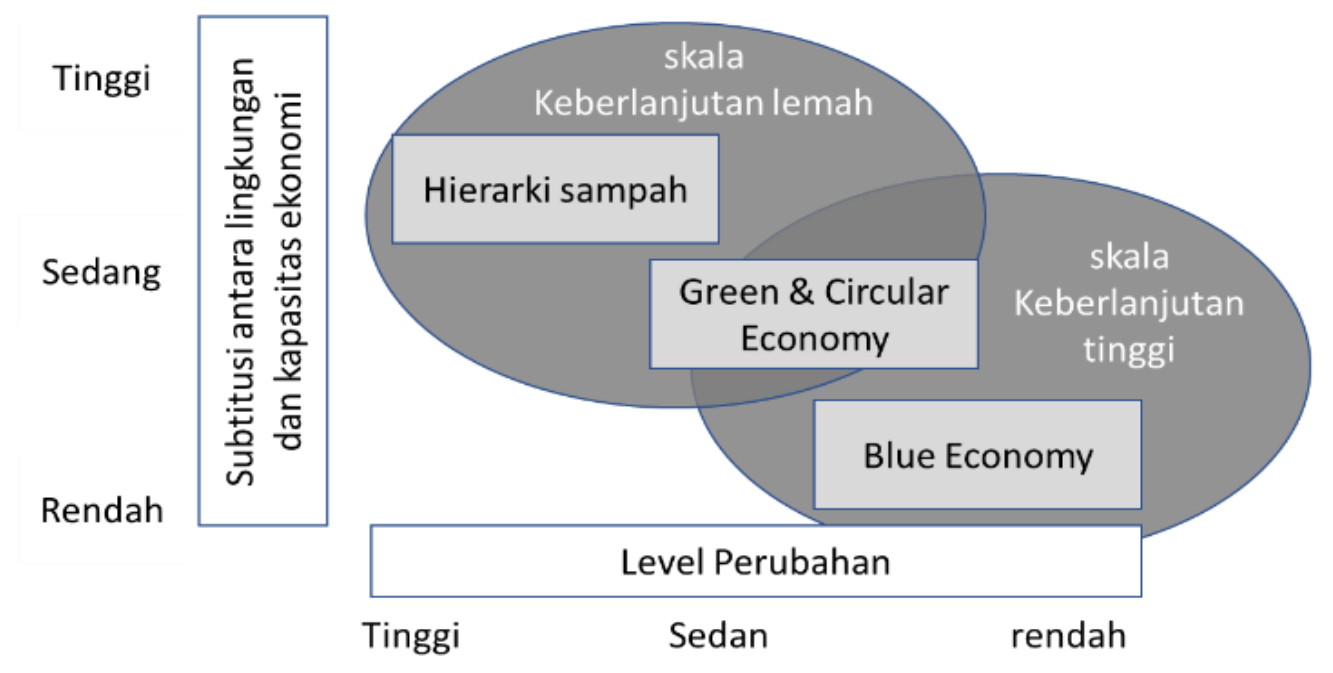

Gambar 3 Klasifikasi konsep ekonomi berkelanjutan Sumber: diadopsi dari Loiseau et al. (2016)

Dari gambar 3, penelitian ini merekomendasikan agar Indonesia menerapkan konsep green atau circular economoy. Hal ini memperhatikan bahwa kebijakan pemerintah yang telah dijalani saat aini atau sebelumnya telah mempertimbangkan konsep ini. Selain itu, konsep green atau circular economy telah mempertimbangkan konsep hierarki sampah, atau dengan kata lain, konsep ini adalah konsep yang lebih lengkap. Pilihan ini merupakan pilihan yang moderat, karena memiliki outcome berupa skala substitusi ekonomi dan lingkungan sedang serta tingkat perubahan yang sedang. Kenapa tidak dengan blue economy? Konsep blue economy membutuhkan waktu dan upaya riset yang lebih lama, di mana kita harus meredesign industri mengadopsi konsep ekosistem. Secara implementasi akan lebih sulit, karena industri harus menginvestasikan biaya yang berpeluang menjadi sunk cost. Namun apa pun kebijakannya, perlu dukungan pemangku kepentingan baik dari segi riset maupun politik.

\section{KESIMPULAN}

Konsep terkait pembangunan berkelanjutan ternyata bukan hal yang baru diperbincangkan. Di tengah banyaknya konsep dan gerakan bisnis berkelanjutan, memiliki keterkaitan satu dengan yang lainnya. Walaupun memiliki keterkaitan, namun setelah dipetakan, terdapat dampak kebijakan yang berbeda antar konsep. Dari hasil pemetaan dan klasifikasi, penelitian ini merekomendasikan agar pemerintah Indonesia menerapkan konsep green economy atau circular economy yang memiliki dampak moderat. Hal ini juga mempertimbangkan telah disisipkannya konsep green economy pada kebijakan pemerintah baik pemerintahan Presiden Susilo Bambang Yudoyono maupun Presiden Joko Widodo walaupun tidak dinyatakan secara tegas.

\section{DAFTAR PUSTAKA}

Addison, T., Arndt, C., \& Tarp, F. (2011). The triple crisis and the global aid architecture. African Development Review, 23(4), 461-478.

Bappenas. (2017). Untuk Mewujudkan Nawa Cita Harus Ada Perubahan Paradigma dalam Perencanaan Pembangunan. Simpul, 29.

Barbier, E. B. (2010). A global green new deal: Rethinking the economic recovery: Cambridge University Press.

Bargh, M. (2014). A blue economy for Aotearoa New Zealand? Environment, development and sustainability, 16(3), 459-470.

Boulding, K. (1966). E., 1966, the economics of the coming spaceship earth. New York.

Bullard, N., \& Müller, T. (2012). Beyond the 'green economy': System change, not climate change? Development, 55(1), 54-62.

Cameron, A., \& Stuart, C. (2012). A guidebook to the Green Economy: Issue 1: Green Economy, Green Growth, and Low-Carbon Development-history, definitions and a guide to recent publications. New York: UNDESA, Division for Sustainable Development, 65. 
Cleveland, C. J., \& Morris, C. G. (2013). Handbook of energy: chronologies, top ten lists, and word clouds: Elsevier.

Cooper, T. (2010). Recycling modernity: waste and environmental history. History Compass, 8(9), 11141125.

D'amato, D., Droste, N., Winkler, K., \& Toppinen, A. (2019). Thinking green, circular or bio: Eliciting researchers' perspectives on a sustainable economy with Q method. Journal of Cleaner Production, 230, 460-476.

Dinarto, D. (2017). Indonesia's Blue Economy Initiative: Rethinking Maritime Security Challenges.

Diyar, S., Akparova, A., Toktabayev, A., \& Tyutunnikova, M. (2014). Green Economy-Innovation-based Development of Kazakhstan. Procedia-Social and Behavioral Sciences, 140, 695-699.

Everest-Phillips, M. (2014). Small, So Simple?: Complexity in Small Island Developing States: UNDP Global Centre for Public Service Excellence.

Fink, A. (2019). Conducting research literature reviews: From the internet to paper: Sage publications.

Green Economy Coalition. (2010). Green, fair and productive: How the 2012 Rio Conference can move the world towards sustainability. Retrieved from

Hunter, J. S., \& Benforado, D. M. (1987). Life cycle approach to effective waste minimization. JAPCA, 37(10), 1206-1210.

Huxley, A.-M. (2015). Australian Blue Paper No 1: The BLUE ECONOMY10 Years -100 Innovations 100 MILLION JOBS. Retrieved from Victoria: www.moss.org.au

ICC. (2012). Green Economy Roadmap. A Guide for Business, Policymakers and Society.: International Chamber of Commerce.

Jackson, T. (1993). Clean Production Strategies Developing Preventive Environmental Management in the Industrial Economy: CRC Press.

Kasztelan, A. (2017). Green growth, green economy and sustainable development: terminological and relational discourse. Prague Economic Papers, 26(4), 487-499.

Kirchherr, J., Reike, D., \& Hekkert, M. (2017). Conceptualizing the circular economy: An analysis of 114 definitions. Resources, conservation and recycling, 127, 221-232.

Korhonen, J., Honkasalo, A., \& Seppälä, J. (2018). Circular economy: the concept and its limitations. Ecological economics, 143, 37-46.

Lienig, J., \& Bruemmer, H. (2017). Recycling Requirements and Design for Environmental Compliance Fundamentals of Electronic Systems Design (pp. 193-218): Springer.

Loiseau, E., Saikku, L., Antikainen, R., Droste, N., Hansjürgens, B., Pitkänen, K., . . Thomsen, M. (2016). Green economy and related concepts: An overview. Journal of Cleaner Production, 139, 361-371.

Lounsbury, M. (1997). Exploring the institutional tool kit: The rise of recycling in the US solid waste field. American Behavioral Scientist, 40(4), 465-477.

Ojovan, M. I., Lee, W. E., \& Kalmykov, S. N. (2019). An introduction to nuclear waste immobilisation: Elsevier.

Pauli, G. A. (2010). The blue economy: 10 years, 100 innovations, 100 million jobs: Paradigm publications.

Pearce, D., Markandya, A., \& Barbier, E. (1989). Blueprint for a green economy. London: Earthscan.

Phillips, P. S., Pratt, R. M., \& Pike, K. (2001). An analysis of UK waste minimization clubs: key requirements for future cost effective developments. Waste management, 21(4), 389-404.

Rosenfeld, P. E., \& Feng, L. (2011). Risks of hazardous wastes: William Andrew.

Sassanelli, C., Rosa, P., Rocca, R., \& Terzi, S. (2019). Circular economy performance assessment methods: A systematic literature review. Journal of Cleaner Production.

Shrum, L., Lowrey, T. M., \& McCarty, J. A. (1994). Recycling as a marketing problem: a framework for strategy development. Psychology \& Marketing, 11(4), 393-416.

Smith, M. S., Cook, C., Sokona, Y., Elmqvist, T., Fukushi, K., Broadgate, W., \& Jarzebski, M. P. (2018). Advancing sustainability science for the SDGs. Sustainability science, 13(6), 1483-1487.

Tam, V. W., \& Tam, C. (2006). Evaluations of existing waste recycling methods: a Hong Kong study. Building and Environment, 41(12), 1649-1660.

Taylor, P. R. (1874). The Kroll Institute for Extractive Metallurgy. Colorado School of Mines.

Tóth, G. (2019). Circular Economy and its Comparison with 14 Other Business Sustainability Movements. Resources, 8(4), 159. 